\title{
Twin-to-twin transfusion syndrome with severe hydrops fetalis in the recipient
}

\author{
*Sathika Amarasekara ${ }^{1}$, Pawani Hewamalage ${ }^{2}$, H V D N Siriwardhane ${ }^{2}$, A P R D Aththanayake A $^{2}$ \\ Medha Weerasekera ${ }^{3}$
}

Sri Lanka Journal of Child Health, 2020; 49(3): 297-299

http://dx.doi.org/10.4038/sljch.v49i3.9154

(Key words: Twin-to-transfusion syndrome, polyhydramnios, oligohydramnios)

\section{Introduction}

Twin-to-twin transfusion syndrome (TTTS) has a prevalence of 1-3 per 10,000 births and contributes to $15-17 \%$ of perinatal mortality in twins ${ }^{1,2}$. It occurs in $10-15 \%$ of monochorionic diamniotic (MCDA) twin pregnancies but is rarer in monochorionic-monoamniotic (MCMA) twin pregnancies ${ }^{2,3}$. The fetuses who survive often have cardiac, neurologic, and developmental anomalies ${ }^{4}$. There are only a few cases of TTTS with hydrops fetalis reported in the literature.

\section{Case report}

A 30-year-old woman, gravida 2 para 1, was transferred to a tertiary care centre from a base hospital at 28 weeks of gestation with evidence of TTTS detected at 27 gestational weeks. The pregnancy was uneventful except for mild lower abdominal pain which she developed around 26 gestational weeks. Transabdominal ultrasound scan done at 27 gestational weeks confirmed MCDA twin pregnancy.

Fetus 1 was found to have polyhydramnios and fetus 2 had oligohydramnios and was diagnosed as Quintero stage 4 TTTS or twin oligohydramniospolyhydramnios sequence (TOPS) ${ }^{4,5}$. There were no major structural anomalies noted in either fetus. The decision was made to deliver the babies by emergency caesarean section immediately due to absent diastolic flow in both fetuses. The caesarean section was done after a single dose of dexamethasone (as time was limited) and

\footnotetext{
${ }^{1}$ Senior Registrar in Paediatrics, ${ }^{2}$ Registrar in Paediatrics, ${ }^{3}$ Consultant Neonatologist, Sri Jayewardenepura General Hospital, Nugegoda. Sri Lanka

*Correspondence: sathika2.ama@gmail.com

(iD)

orcid.org/ 0000-0002-0018-4597
}

(Received on 06 February 2019: Accepted after revision on 22 March 2019)

The authors declare that there are no conflicts of interest

Personal funding was used for the project.

Open Access Article published under the Creative

Commons Attribution CC-BY cC (i) magnesium sulphate as per local protocol. The first twin was the one with hydrops and weighed $1800 \mathrm{~g}$. He was grossly oedematous, plethoric and had gasping breathing with absent heart sounds (Figure1). The Apgar score was 3 at 1 minute and all attempts at resuscitation failed.

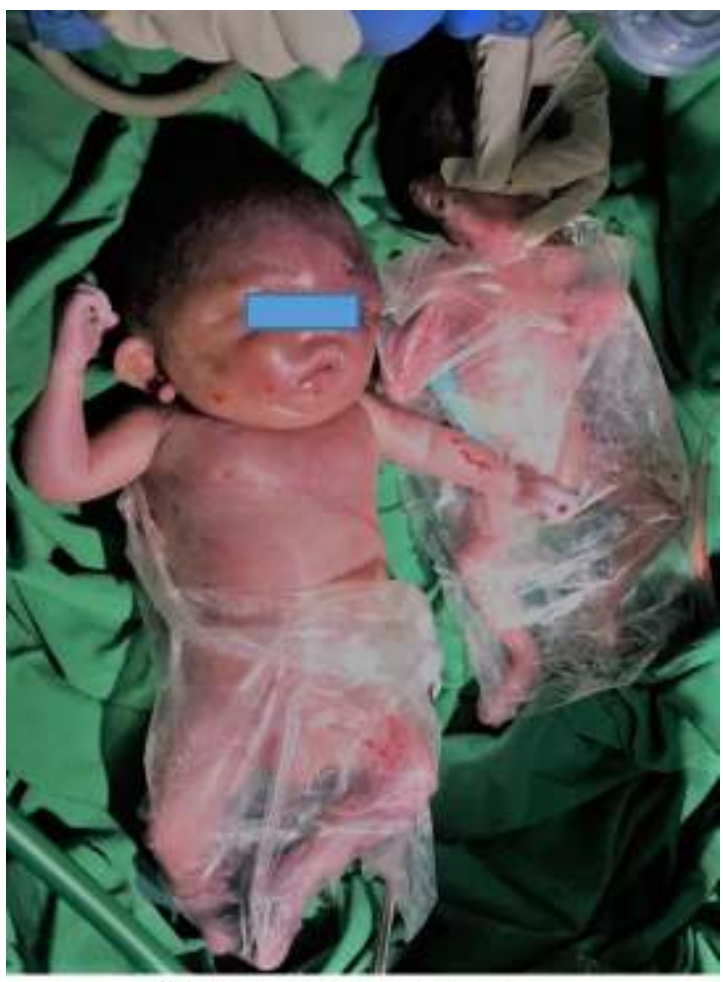

Figure 1: Twins at birth

The second twin weighed $790 \mathrm{~g}\left(<10^{\text {th }}\right.$ percentile $)$ and Apgar score was 2 and 7 at 1 and 5 minutes respectively. Anhydramnios was noted at birth. He needed mechanical ventilation and surfactant therapy for severe surfactant deficient lung disease. $\mathrm{He}$ was found to have severe anaemia with a haemoglobin level of $7 \mathrm{~g} / \mathrm{dl}$ and needed packed cell transfusion on the first day of life. There was no evidence of renal insufficiency or hypocalcaemia during the immediate newborn period. The ultrasonography of the brain was normal. The baby was discharged on day 61 of life.

\section{Discussion}

There are three types of vascular anastomosis in monochorionic placentae and TTTS commonly 
result from unequal transfusion of blood from one fetus (donor) to the other fetus (recipient) via artery-to-vein anastomosis through shared placental cotyledon ${ }^{1-6}$. TTTS presents in the mid-trimester with discordant amniotic fluid volumes due to under-perfusion of the donor twin and overperfusion of the recipient twin ${ }^{1-9}$. The donor twin develops hypovolaemia resulting in oligo/anuria and oligo/anhydramnios ${ }^{6,7}$. In the absence of urine, fetal bladder will not be visualized by ultrasonography ${ }^{2,6}$. Ultrasound may also show discordant growth $(>20 \%)$, intrauterine growth restriction (IUGR) and abnormal umbilical (absent/reversed) and middle cerebral artery Doppler velocities ${ }^{1,7}$.

Over perfused recipient develops polyuria and polyhydramnios ${ }^{2,6,7}$. The volume overload may progress to cardiac dysfunction with cardiomegaly, tricuspid regurgitation, ventricular hypertrophy and ultimately right ventricular outflow tract obstruction ${ }^{1,2}$. Either twin can develop hydrops fetalis. The donor becomes hydropic as a result of anaemia and high-output heart failure whereas in the recipient the aetiology for hydrops is hypervolaemia. Hypertension, disseminated intravascular coagulation (DIC) and hyperbilirubinemia are the other complications seen in the recipient twin after birth ${ }^{6}$.

Diagnosis of TTTS can be made with ultrasonographic evidence of oligohydramnios in donor's sac and polyhydramnios in recipient's sac in monochorionic twin pregnancies ${ }^{6,7}$. It is the main diagnostic criterion of TTTS (twin oligohydramnios and polyhydramnios sequence TOPS) ${ }^{7,8}$. In addition, significant disparity in size of the fetuses with monochorionic placentation is also suggestive of TTTS $^{6}$. Thus, the donor is growth restricted and can be anaemic with poor circulation. It may develop hypocalcaemia, hypoglycaemia and elevated creatinine due to renal dysfunction. The recipient is large for gestation and is plethoric due to polycythaemia. After birth, $20 \%$ weight discrepancy and haemoglobin difference of $5 \mathrm{~g} / \mathrm{dl}$ in donor and the recipient twin can be appreciated ${ }^{4,6,8}$.

There are a variety of therapeutic options available for TTTS. Serial amnio-reduction (AR) is the simplest treatment option to control the polyhydramnios and to prolong the gestation ${ }^{2,5}$. However, it carries a high rate of perinatal morbidity and mortality ${ }^{2}$. Fetoscopic laser photocoagulation of placental vascular anastomosis is the next option which restores two fetal circulations and carries a better outcome than $\mathrm{AR}^{7}$. However, it is performed only in a few centres around the world and is reserved for more severe cases. Once all treatment options fail and intrauterine death of one twin appears imminent, selective fetocide may be performed ${ }^{2}$.

The optimum timing of the delivery depends on multiple factors. Severe fetal growth restriction, preterm labour and non-reassuring biophysical profile warrant preterm delivery ${ }^{6}$. Post-natal management is directed towards management of prematurity related problems, anaemia, polycythaemia, and hydrops fetalis. Monitoring of renal function should be done in the donor twin, as it has increased risk of transient renal insufficiency, acute kidney injury and permanent tubular dysfunction $^{8}$. Echocardiography is warranted due to increased risk of cardiac dysfunction in recipient ${ }^{1}$.

Severe TTTS (Quintero stage >III) carries a 70$100 \%$ perinatal mortality rate especially when presents before 26 weeks of gestation ${ }^{1}$. Premature delivery is frequently seen in mild to moderate cases of TTTS. The prognosis dependent upon the gestational age at birth and the degree of brain ischaemia during intrauterine life. Fetal brain ischaemia may result in periventricular leukomalacia, porencephaly, microcephaly and cerebral palsy ${ }^{6,8}$. Both the donor and recipient are at equal risk of theses neurological sequelae ${ }^{8}$. Intrauterine death of one twin is associated with adverse neurological outcome in $25 \%$ of the surviving twin ${ }^{6,7}$.

\section{References}

1. Studio B. Publications \& Guidelines SMFM.org - The Society for MaternalFetal Medicine [Internet]. Smfm.org. 2019 [cited 28 January 2019]. Available from: https://www.smfm.org/publications/80twin-twin-transfusion-syndrome

2. Pasupathy D, Denbow M, Kyle P. Antenatal diagnosis and fetal medicine. In: Rennie JM, editor.5th ed. Text book of Neonatology. London: Elsevier; 2012. p 142- 60. https://doi.org/10.1016/B978-0-70203479-4.00009-X

3. Umur A1, Van Gemert MJ, Nikkels PG. Monoamniotic-versus diamnioticmonochorionic twin placentas: anastomoses and twin-twin transfusion syndrome. American Journal of Obstetrics and Gynecology 2003; 189(5):1325-9. https://doi.org/10.1067/S00029378(03)008 $11-1$

4. Johnson A, Papanna R. Twin-twin transfusion syndrome: Management and outcome. Available from: 
https://www.uptodate.com/contents/twintwin-transfusion-syndrome-managementand-outcome? csi=6b102e67-1ae3-498dbe $927 \mathrm{c} 809 \mathrm{f} 0516 \mathrm{~d} 3 \&$ source $=$ contentShare \#H1.

5. Van den Wijngaard J, van Gemert $M$, Lopriore E, Vandenbussche F, Nikkels P, VanBavel E. Case report: Twin-to-twin transfusion syndrome resulting from placental collateral artery development. Placenta 2008; 29(2):220-3. https://doi.org/10.1016/j.placenta.2007.10. 013

PMid: 18068761

6. Twin-to-twin transfusion syndrome: Background, pathophysiology, epidemiology. Emedicine.medscape.com. 2019 [cited 23 January 2019]. Available from:

https://emedicine.medscape.com/article/27 1752-overview
7. Rossi A, D' Addario V. Diagnosis and management of twin-twin transfusion syndrome. Donald School Journal of Ultrasound in Obstetrics \& Gynecology 2012; 6:286-9.

https://doi.org/10.5005/jp-journals-100091251

8. Patil P, Kumar A, Shrikhande DY, Reddy RS, Panwar S. Twin to twin transfusion syndrome. International Journal of Healthcare and Biomedical Research 2014; 2(4):127-30.

9. Simpson LL. Twin-twin transfusion syndrome. SMFM. American Journal of Obstetrics and Gynecology 2013; 208(1):3-18.

https://doi.org/10.1016/j.ajog.2012.10.880 PMid: 23200164 